\title{
Laboreal
}

Volume $11 \mathrm{~N}^{\circ} 1$ | 2015

Modos de vida e trabalho

\section{Os ingredientes da competência de gerentes de hotéis}

Los ingredientes de la competencia de los gerentes de hotel Les ingrédients de la compétence des gestionnaires d'hôtels

The ingredients of hotel managers' competence

\section{Edil Ferreira da Silva, Anísio José da Silva Araújo, Francinaldo do Monte Pinto, Paulo César Zambroni-de-Souza, Euda Kaliani Gomes Teixeira Rocha e Thaís Augusta Cunha de Oliveira Máximo}

\section{OpenEdition}

Edição electrónica

URL: http://journals.openedition.org/laboreal/4332

DOI: 10.4000/laboreal.4332

ISSN: 1646-5237

\section{Editora}

Universidade do Porto

Refêrencia eletrónica

Edil Ferreira da Silva, Anísio José da Silva Araújo, Francinaldo do Monte Pinto, Paulo César Zambronide-Souza, Euda Kaliani Gomes Teixeira Rocha e Thaís Augusta Cunha de Oliveira Máximo, « Os ingredientes da competência de gerentes de hotéis », Laboreal [Online], Volume $11 N^{0} 1$ | 2015, posto online no dia 01 julho 2015, consultado o 11 outubro 2019. URL : http://journals.openedition.org/ laboreal/4332 ; DOI : 10.4000/laboreal.4332

Este documento foi criado de forma automática no dia 11 outubro 2019.

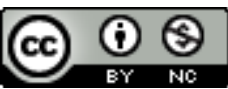

Laboreal está licenciado com uma Licença Creative Commons - Atribuição-NãoComercial 4.0 Internacional. 


\title{
Os ingredientes da competência de gerentes de hotéis
}

\author{
Los ingredientes de la competencia de los gerentes de hotel \\ Les ingrédients de la compétence des gestionnaires d'hôtels \\ The ingredients of hotel managers' competence
}

Edil Ferreira da Silva, Anísio José da Silva Araújo, Francinaldo do Monte

Pinto, Paulo César Zambroni-de-Souza, Euda Kaliani Gomes Teixeira

Rocha e Thaís Augusta Cunha de Oliveira Máximo

\section{NOTA DO EDITOR}

http://dx.doi.org/10.15667/laborealxi0115efs

Manuscrito recebido em: novembro 2014

Aceite após peritagem: maio 2015

\section{Introdução}

1 No presente artigo procuramos focalizar o tema da competência, que ganhou destaque a partir das mudanças que se seguiram à crise dos anos 1970, afirmando-se como um novo paradigma de gestão. Em virtude de a competência constituir um agir em situação, procuramos discuti-la nesse artigo estabelecendo conexões com uma realidade empírica específica, a dos gerentes de hotéis das cidades de João Pessoa e Campina Grande, Brasil. 


\subsection{0 trabalho dos gerentes: autonomia, subordinação e importância estratégica}

2 O tema do trabalho de gerentes permeia várias investigações que vêm sendo desenvolvidas no Grupo de Pesquisa Subjetividade e Trabalho - GPST (Lima \& Zambroni, 2013; Máximo, 2009; Máximo, 2012; Soares, 2014), ao qual se vincula a maioria dos autores desse artigo, porque entendemos que, apesar da função gerencial possuir certo status social, a academia precisa ainda debruçar-se sobre ele.

3 As análises sobre o trabalho gerencial não tiveram, de acordo com Luci e Szlechter (2014), a merecida atenção por parte dos intelectuais seja devido a preconceitos (por exemplo, considerar que os quadros médios das empresas faziam parte da classe capitalista), seja devido à falta de base teórica que não pôde desenvolver-se porque outros atores sociais se mostraram mais atrativos para estudos. De acordo com esses autores, quando o gerente é considerado na sua condição de assalariado, criam-se as condições para enxergar a complexidade deste grupo, que cumpre um papel subordinado ao capital e ao mesmo tempo se encontra inscrito numa relação de confiança com o empregador. "Isto nos permite pensar a unidade e a tensão existente entre a dimensão objetiva (subordinação salarial) e outra mais subjetiva (a relação de confiança) própria de sua condição social" (p.119).

4 Sempre se invocou o atrativo da autonomia no trabalho gerencial ancorada, de um lado, na ausência de prescrições operacionais que, em contrapartida, exige do gerente uma fina capacidade de tradução das diretrizes do capital e, de outro lado, na autonomia na gestão do tempo, no fato de não precisar cumprir horários rígidos (o que acaba muitas vezes fazendo que cumpram uma carga horária acima da regulamentada por lei). Esta autonomia, segundo os autores, não deixa de ser relativa, ambígua e contraditória, pois "o estímulo à iniciativa e a livre cooperação não é tolerada, senão quando responde aos objetivos da direção da empresa. A autonomia possui um alto custo para os assalariados. A iniciativa, a criatividade, a autenticidade requerem uma mobilização da subjetividade" (Luci \& Szlechter, 2014, p. 133). Ou seja, estamos diante de um trabalho com exigências subjetivas consideráveis, sobretudo se considerarmos que, sobre os quadros médios deposita-se a responsabilidade de executar o planejamento das empresas (partimos de uma hierarquia em que acima se localizam os executivos, diretores, altos gerentes e, mais abaixo, os supervisores).

5 Convocando os estudos em ergonomia, Mascia (2007) defende que os gerentes são trabalhadores como os demais pelo que julga importante que a sua atividade seja objeto de investigações que procurem revelar as dificuldades que enfrentam e os riscos à saúde aos quais estão expostos. Mascia (2007) defende igualmente que as mudanças visadas pela ergonomia no âmbito do trabalho de gerentes dificilmente seriam conseguidas sem um conhecimento do seu trabalho, especialmente porque essa categoria de trabalhadores tem um papel estratégico na organização.

6 Apesar da multiplicidade de tarefas que envolvem o trabalho de gerentes, elas podem, segundo Mascia (2007), ser agrupadas em quatro categorias: relacional, gestão, técnica e comercial. As tarefas relacionais implicam principalmente "estar à escuta de seus subordinados" (Mascia, 2007, p. 612), mas envolve também atividades de animação e coordenação de pessoas. As tarefas de gestão, por sua vez, envolvem o planejamento, a organização e a gestão das operações, que contam, em geral, com o suporte de sistemas informatizados. Observa-se uma tendência a transformar cada vez mais os gerentes em 
"Gestores de Pessoas" (denominação que se afirma crescentemente em substituição a de Gestores de Recursos Humanos), o que significa confiar-lhes funções antes assumidas de forma exclusiva por órgãos - setores, divisões, departamentos de Recursos Humanos - que cumpriam esse papel (e ainda o cumprem em certa medida já que não desapareceram inteiramente, embora tenham sido reduzidos em tamanho e importância) os quais, por sua vez, têm as suas funções redefinidas no sentido de dar suporte aos gerentes nesta sua configuração. Nesse caso, as tarefas mais usuais transferidas aos gerentes remetem à aplicação das políticas gerais de gestão de pessoas (definidas em outras instâncias), tais como: avaliação, construção dos planos de capacitação, definição de promoções, progressões, entre outras. No que tange às tarefas técnicas, a exigência de domínio específico pode variar dependendo do contexto considerado. No caso de gerentes de hotéis, a exigência de domínio das tecnologias próprias ao meio hoteleiro depende do porte do hotel e das políticas e práticas organizacionais utilizadas.

7 As tarefas comerciais, presentes, sobretudo, no setor de serviços (como é o caso dos hotéis), sofreram importantes mudanças no âmbito aqui considerado, já que os gerentes passaram a assumir com mais ênfase a relação com a clientela, para a qual devem esmerar-se na apresentação e na venda do cardápio de serviços. Trata-se da figura, cada vez mais comum, do gerente 'vendedor', cujo trabalho deve ser exercido cada vez mais no campo, fora dos limites do 'escritório' em que se encontrava encerrado.

8 Se considerarmos a condição atual dos gerentes, constata-se, portanto, uma ampliação das responsabilidades, especialmente porque vivemos um contexto, como bem enfatizam Davel e Melo (2005), de organizações reestruturadas, que "passaram pela qualidade total, pelo enxugamento de efetivos, pela redução de níveis hierárquicos, pela terceirização de serviços, pela informatização (...)" (p. 38). Diante disso, supomos haver conhecimento insuficiente sobre o conteúdo do trabalho gerencial e como tais mudanças o tem reconfigurado. O nosso interesse, portanto, é aproximar-nos do trabalho dos gerentes de hotéis, buscando apreendê-lo na sua complexidade e movimento, procurando torná-lo mais visível.

\subsection{A expansão do setor de turismo}

O setor de turismo abrange vários tipos de estabelecimento, dentre os quais a hotelaria ocupa lugar de destaque. De acordo com a Organização Mundial do Turismo (OMT), o crescimento desse setor tem beneficiado "indivíduos, famílias e comunidades inteiras, tratando-se da maior atividade do comércio internacional, empregando milhares de pessoas, direta ou indiretamente, em hotéis, transportadoras, locadoras de veículos, agências de viagens" (Gorini \& Mendes, 2005, p.113-114). Trata-se de um setor que se consolida a cada ano, atravessando fronteiras entre diferentes países do mundo, pelo incremento dos segmentos de transportes (aéreo, rodoviário, pluvial e marítimo) e de agências de turismo.

O turismo, no Brasil, notadamente no setor hoteleiro, passou por um período de estagnação no final década de 1980 e de recuperação em meados dos anos 1990, acompanhando o crescimento da economia do país. Este impulso na hotelaria ocorreu por vários motivos, tais como: estabilização da inflação; investimento em infraestrutura; entrada de capital estrangeiro, em parte canalizado para a criação de 
novas empresas; oferta e diversificação de serviços em escala global (Gorine \& Mendes, 2005).

11 No Brasil, o segmento hoteleiro tem contribuído para a oferta de emprego ao absorver uma parcela dos trabalhadores cujos postos de trabalho foram extintos dos parques industriais (Fernandes, Nogueira, Cruz, Figueiredo \& Ávila, 2010).

João Pessoa e Campina Grande, cidades onde se realizou a pesquisa objeto desse artigo, são os dois pólos turísticos mais importantes do Estado da Paraíba e que concentram a maior parte da rede hoteleira. O turismo nessas cidades, refletindo as condições econômicas favoráveis apontadas anteriormente, vem crescendo num ritmo acelerado. Pelo que se colheu nas conversas iniciais mantidas com operadores do turismo para confecção do projeto de pesquisa e, posteriormente, nas entrevistas realizadas, o crescimento da rede hoteleira tem favorecido a migração de uma gestão familiar para uma gestão profissional, capitaneada, sobretudo, pela presença de hotéis ligados a grandes redes hoteleiras, nacionais e internacionais. Tal fato associado ao flagrante crescimento da rede hoteleira e a posição privilegiada dos gerentes, que lhes faculta enxergar o segmento turístico não de forma compartimentada, mas na sua globalidade, foram os argumentos que nos convenceram que o presente estudo representava uma boa entrada para mapear transformações que se processam no trabalho de gerentes de hotéis e, desse modo, encontrar os elementos para alimentar mudanças em vários níveis, ou seja, no trabalho dos gerentes propriamente dito, no nível da gestão hoteleira e, mais amplamente, no setor turístico paraibano.

\subsection{0 significado da noção de competência}

\subsubsection{A competência: uma questão insolúvel, mas necessária}

13 Para abordar com rigor o tema da competência, concordamos com Schwartz (2000), para quem ela apresenta-se como uma questão insolúvel, mas cujo enfrentamento é necessário. Neste sentido, Schwartz (2010, p. 205) afirma ser "difícil dizer alguma coisa das competências sem trair o que elas são: antes de tudo um 'agir' aqui e agora”. Nas palavras do autor:

(...) acho que este é um paradoxo incontornável: é um exercício necessário para uma questão insolúvel. Não se chegará jamais a objetivar a competência. Mas tentar fazê-lo me parece normal, porque, repito, todo mundo avalia, talvez intuitivamente, e o faz desde o momento em que se empreende algo junto (Schwartz, 2010, p. 221).

14 Nessa mesma linha, Jobert (2003), ao afirmar que o saber-fazer não se diz facilmente e que a competência só é observável no movimento que a produz, defende que a competência não é um objeto passível de ser nomeado e inventariado. Para ele,

(...) se a competência é uma capacidade situada, é sobre a situação que deve incidir a ação. Para o administrador, como também para o formadorconsultor, profissionalizar consiste em criar as condições favoráveis ao desenvolvimento das competências. Condições técnicas para que a organização do trabalho abra espaço à invenção; condições sociais para que a contribuição subjetiva própria dos agentes seja objeto de um reconhecimento (p. 225). 
Estamos de acordo com esses autores (Jobert, 2003; Schwartz, 2010), para quem é necessário avaliar as competências, mas que este processo, sempre parcial, deve continuamente levar em conta situações vivas de trabalho, no encontro dos sujeitos com a atividade.

\subsubsection{Contra o modelo de mapeamento de competências}

Em contraste aos autores apresentados acima, encontram-se na literatura e nas práticas empresariais modelos de mapeamento de competências que vão em uma linha diferente da que defendemos neste artigo, tendo em vista que os mesmos parecem abordar as competências de modo estanque, desconsiderando o movimento da atividade. Nesse sentido, Ribeiro (2009) e Spector (2002) afirmam que o trinômio composto por Conhecimentos, Habilidades e Atitudes (ou como se costuma designar CHA, sob a forma de sigla), consolidou-se como um parâmetro estável e quase consensual de análise dos requisitos necessários para um desempenho eficiente e eficaz nos processos de trabalho.

Ora, nossa compreensão é que tal modelo reproduz a lógica taylorista do posto de trabalho, que considera que as pessoas atendem (ou não) a determinados perfis prédeterminados e que os processos de seleção, treinamento e avaliação devem buscar conhecer esses perfis para então poder decidir se os trabalhadores se encaixam ou não neles. Tal procedimento não constitui nenhuma novidade, mas apenas nomeia diferentemente uma velha prática de gestão herdada do Taylorismo.

18 Felizmente, nem todas as propostas de abordagem das competências se respaldam nessa lógica. Há em algumas delas a conviç̧ão de que apenas uma parcela das competências é possível repertoriar e servir de base a um programa de formação. Para a outra parcela das competências, que são convocadas pelos imprevistos, pelas insuficiências da prescrição, a alternativa é contribuir para a constituição de um background que possa permitir aos trabalhadores encontrar por si próprios os modos de enfrentamento pertinentes a cada situação.

19 Contudo, se por um lado, a crise do modelo da prescrição fez com que a discussão acerca da competência ganhasse cada vez mais projeção nos mundos acadêmico e do trabalho; por outro lado, observa-se atualmente uma utilização muito inflacionária da palavra competência. Schwartz (2010) critica o fato de que os diferentes entendimentos em torno desse tema acabaram por gerar uma série de tentativas de "fechar uma lista de competências, enfim 'traços de competências', para saber se uma pessoa possui ou não" (p. 205). Ao fazer isso, existe "um risco de voltar a enclausurar a potencialidade aberta (...). O manuseio desta noção de competência apresenta um poderoso desafio e é por isso que é interessante precisar um pouco as coisas, se isso for possível" (p. 205206).

20 É precisamente no âmbito desta finalidade que, a seguir, procuramos explorar melhor o significado da emergência da noção de competência explicitando, na sequência, as decisões metodológicas que tomamos na presente pesquisa - o que sustentará a análise do material empírico que pudemos acessar nesse estudo. 


\section{A emergência da competência}

\subsection{A derrocada do Fordismo enquanto modelo de organização da produção, de acumulação de capital e de regulação social}

Durante os anos de ouro do Fordismo (os chamados "trinta gloriosos"), período que se estendeu do final da $2^{\mathrm{a}}$ Guerra Mundial até meados dos anos 1970, quando o capitalismo viveu um crescimento econômico excepcional, o modo fordista de produção parecia fora de contestação e, portanto, imune às críticas de que era alvo por parte dos movimentos sociais, especialmente o movimento sindical, e pelos próprios trabalhadores. Ainda que seus impasses fossem reconhecidos, inclusive pela gerência, o ambiente econômico fazia com que as críticas ao fordismo perdessem força antes mesmo que causassem algum impacto negativo na sua imagem social. Afinal, o Fordismo tinha como aliado o Estado de Bem-estar (nunca suficientemente estabelecido no Brasil), o que certamente contribuiu para que seu modo de gestão impositivo sobrevivesse tanto tempo sem modificações profundas.

Quando o cenário se alterou e a relativa previsibilidade que reinou durante os "trinta gloriosos" cedeu lugar a um ambiente de imprevisibilidade, de incertezas, de mudanças frequentes e descontínuas, descortinou-se toda a fragilidade do edifício fordista encoberta pela fumaça do crescimento econômico. Inclusive revelou-se o fato de que seu funcionamento estava parcialmente ancorado na inventividade dos trabalhadores que, embora sem autorização e reconhecimento oficiais, preenchia eficazmente as lacunas deixadas pela insuficiência da prescrição. É nessas circunstâncias que o ideal de tudo prever e codificar, reduzindo ao máximo as possibilidades de arbitragem por parte dos trabalhadores, revela-se com nitidez um alvo inalcançável. Urge então revê-lo auscultando os sinais dos tempos. A crise que se abateu sobre o capitalismo em meados dos anos 1970 foi então o ventre que deu vida à noção de competência.

Evidentemente, vários antecedentes já sinalizavam para a crítica, no seio do próprio capitalismo, da lógica gerencial e produtiva do Fordismo. Entre eles a queda na produtividade do trabalho, a elevação dos níveis de inflação, a desaceleração do crescimento econômico e o esgotamento dos mercados consumidores (Heloani, 2003). Antes disso, reveladoras da procura de modelos organizacionais alternativos, as experimentações ocorridas nas minas de carvão de Durham nos anos 1950 sob o comando de pesquisadores do Instituto Tavistock de Londres e que forjaram o que hoje se conhece por Abordagem sócio-técnica, já sinalizavam para o fato de que o aumento da produtividade poderia ocorrer por meio de formas de organização do trabalho que não privilegiassem a fragmentação do trabalho, como era o caso do Taylorismo e do Fordismo. Autonomia, participação na gestão, grupos de trabalho, palavras proscritas no dicionário taylorista, renasciam em meio às transformações ocorridas no ambiente das empresas.

Também as mudanças econômicas, políticas, tecnológicas, culturais e sociais que se seguiram aos anos 1960, algumas delas capitaneadas por movimentos que, em vários países europeus, se revelaram em maio de 1968, também aumentaram a pressão por mudanças na organização do trabalho prevalente até então. Desse modo, um novo arcabouço conceitual começa a ser construído para responder aos impasses gerados pela crise, de modo a permitir a continuidade da reprodução do capital. É quando a noção de competência começa a ganhar um lugar de destaque sem que, entretanto, 
tenha varrido da cena os seus antecessores (o Taylorismo e o Fordismo) que permanecem como guias para inúmeras situações no mundo do trabalho. Jobert (2003) reflete sobre essa importante mutação:

Quando o domínio exógeno da atividade encontra seus limites na imprevisibilidade e na complexidade das situações concretas de produção, convém recorrer à habilidade própria dos operadores e à sua capacidade de renormatizar as situações [...] Para esse fim, não basta formar, é preciso profissionalizar os trabalhadores, levando-os a assumir mais sua subjetividade, a mobilizar sua inteligência criativa e a tomar decisões em função da reconfiguração incessante das situações concretas (p. 223).

\section{fontes:}

[...] o crescimento de situações imprevisíveis nos sistemas automatizados, a produção em pequenas séries, a elevação das exigências de qualidade e o crescimento de atividades de serviço são evoluções que tornam as tarefas cada vez mais dificilmente prescritíveis e aproxima os trabalhadores taylorizados dos trabalhadores do social, da educação, da assistência, cuja atividade é, por natureza, menos fácil de racionalizar (p.223).

\subsection{A ascensão do serviço}

Embora o setor de serviços tenha sido objeto de intensa racionalização, esta, segundo Gadrey (2001), direcionou-se mais a serviços onde o componente "relacionamento entre pessoas” é relativamente reduzido. Tais serviços “(...) são mais suscetíveis de ser 'industrializados', se caracterizarmos dessa forma os processos que se baseiam ao mesmo tempo na padronização dos processos e dos resultados e na 'mecanização' das operações, no sentido de substituição do trabalho vivo por máquinas (...)" (Gadrey, 2001, p. 39). Esse autor sublinha, contudo, que os serviços que mais se expandem e, portanto, são menos suscetíveis de ser industrializados, são precisamente aqueles que envolvem relacionamentos ou as chamadas relações de serviço que, por sua vez, abrangem "(...) interações de informações, interações verbais, contatos diretos e trocas interpessoais entre os produtores e os beneficiários do serviço" (p. 39). Isso não significa dizer que esses serviços não passem por inovações técnicas e organizacionais, porém estas ocorrem mais pela via da complementariedade entre capital e trabalho do que pela via da substituição [1]. É nessa categoria de serviços, nas quais as "relações de serviços" predominam, que se insere o trabalho de gerentes de hotéis, objeto de nosso estudo.

Ora, é neste contexto que Jobert (2003) realça quanto a competência é uma noção difícil de delimitar, pois implica um delicado manejo teórico-prático da noção de competência, seja em função da dificuldade de simbolizar pela linguagem as dificuldades que se foi levado a ultrapassar para chegar a um determinado resultado, seja devido ao fato de que "a competência só é observável no movimento que a 'produz"' (p. 223). 


\subsection{O risco da individualização}

qualificação de um posto de trabalho ou de um indivíduo repousa sobre a prescrição, a codificação e a previsão. É bom lembrar também que os tempos do Fordismo foram sustentados pelo principio de uma coesão social garantida graças à regularidade da negociação entre os pareceres sociais - por exemplo no que diz respeito aos níveis de qualificação e, estritamente associadas, às remunerações das diferentes categorias de trabalhadores assalariados. A competência, ao invés, está remetida ao indivíduo, às suas habilidades, aos seus saberes, às suas arbitragens investidas numa ação que, pela sua natureza, jamais se estabiliza e que é invadida incessantemente pela história e seus acontecimentos. Ela é requisitada precisamente quando os padrões de referência anteriores se mostram discrepantes em relação às demandas concretas. A obtenção do resultado depende, nesse sentido, "do investimento objetivo do operador, de seu desejo, e de sua capacidade de desenvolver sua inteligência lá onde a regra falha ou se mostra impertinente" (Jobert, 2003, p. 223). Como pontuamos acima, é justamente aí que se situa o risco da abertura para uma abordagem individualizada da competência (Stroobants, 2006), que acaba facilitando a dissolução dos coletivos e culpabilizando o trabalhador pelos fracassos no trabalho.

Segundo Stroobants (2006, p. 78), a própria noção de competência nunca entrou em "acordo sobre uma definição rigorosa", e isso pode trazer consigo diversos problemas, em especial, a individualização dos processos de avaliação, associada à individualização dos sistemas de remunerações. Isso ocorreria já que, mesmo que se requeira “(...) a faculdade de mobilizar rede de atores em torno das mesmas situações, (...) a faculdade de fazer com que esses atores compartilhem as implicações de suas ações" (Zarifian, 2001a, p. 74): a finalidade abarca todos os aspetos da atividade profissional, com o risco de "listar exaustivamente as competências e remetê-las inteiramente à pessoa" (Schwartz, 2010, p. 217).

\section{4. Os possíveis ingredientes da competência}

Partindo deste desafio, Schwartz assinala, todavia, que pode "existir aí uma dinâmica virtuosa de avaliação de competências, pelo vai e vem entre o que pode ser saúde para a pessoa e o que pode ser transformado em meio de trabalho (...): transformar o que deve ser transformado, se não se quer bloquear desenvolvimentos de competências" (2010, p. 217). Apresentamos então neste artigo uma pesquisa realizada nos anos de 2009 a 2011 que buscou captar, junto a gerentes de hotéis, a(s) competência(s) onde elas se apresentam vivas, ou seja, em situações reais, sabendo que seus resultados são sempre parciais. Embora reconhecendo os limites de tais pesquisas para enfrentar este problema insolúvel, queremos dar-lhes visibilidade e colocá-las em debate, adimitindo que "tentar engrenar uma dinâmica virtuosa das competências é sem dúvida bastante raro, mas é certamente uma dinâmica ou um processo a defender" (Schwartz, 2010, p. 217).

31 Schwartz (2010) acaba, efetivamente, por defender que, se não é possível nem desejável estabelecer uma lista de competências como algo recomendável para determinado meio de trabalho, é necessário reconhecer que agir em competência supõe uma combinação de ingredientes que estariam presentes em cada situação em graus variados de

Laboreal, Volume $11 \mathrm{~N}^{\circ} 1$ | 2015 
intensidade. Isso não significa dizer que, com tais ingredientes, poderia se fazer uma receita, uma listagem de características, reproduzível em qualquer situação, negando a sua singularidade. Ao contrário, trata-se de reconhecer que, em cada trabalho, o agir em competência supõe combinar uma série de elementos, sempre de forma situada, portanto nunca completamente antecipável, para fazer com qualidade o que se requer de quem trabalha. É sabido que para o autor, de forma geral, é impossível antecipar totalmente qualquer situação de trabalho, já que há sempre infidelidades do meio a serem geridas por cada trabalhador em cada situação específica (Schwartz, 2010). No entanto, não se pode negligenciar que há um conjunto de fatores que, conjugados, permitem que cada um faça a gestão daquelas infidelidades de maneira a produzir os resultados esperados. Ou seja, não se trata de juntar os elementos seguindo uma determinada ordem para que o trabalho seja realizado a contento. Mas trata-se de evidenciar que há elementos que, se conjugados na renormatização realizada pelos trabalhadores, permitirão o sucesso do trabalho e o desenvolvimento das potencialidades de cada um.

32 Essa postura implica "recusar a ilusão de uma definição possível da competência separada das condições que, no dia-a-dia, dão pura e simplesmente conta de nossa capacidade de viver" (Schwartz, 2000, p. 483).

Schwartz acaba assim por tentar distinguir o que designa por "Ingredientes" de competência, que de cinco (Schwartz, 2000) passaram a ser seis (Schwartz, 2010) - a saber:

- "O primeiro (...): o relativo domínio dos protocolos numa situação de trabalho" (p. 207). Tal ingrediente supõe um descentramento para se compreender as regras, as normas, os conceitos, ou seja, uma descontextualização dos trabalhadores com relação à sua situação pessoal, suas características, seus desejos. Requer disciplina, por ser essencialmente conceitual;

- "O segundo (...): relativo à incorporação do histórico de uma situação de trabalho" (p. 208). Esse ingrediente é bastante distinto do anterior. Ele diz respeito à "capacidade de se deixar apropriar (...) pela dimensão singular da situação, pelo histórico, pela dimensão de 'encontro de encontros"' (p.208). Se o primeiro ingrediente requer abstração, distanciamento, o segundo supõe a compreensão e a capacidade de agir em situações concretas, específicas, singulares;

- "O terceiro (...): a capacidade de articular a face protocolar e a face singular de cada situação de trabalho" (p. 210). Esse ingrediente diz respeito a colocar em sinergia os dois primeiros, ou seja, em compreender o que há de padrão em uma dada situação e, ao mesmo tempo, perceber o que ela tem de distinto, próprio, para que a intervenção seja bem sucedida. Certamente os dois primeiros se mostrarão mais eficazes em uma situação real se colocados em interação;

- "O quarto (...): o debate de valores ligado ao debate de normas, as impostas e as instituídas na atividade" (p. 213). Pode-se com ele debater a questão da motivação, que não deve nunca ser colocada sob os ombros apenas de quem trabalha, mas, ao contrário, deve ser entendida a partir da interação desta pessoa, portadora de valores, com o meio, nunca neutro, sempre também repleto de valores. Nas palavras de Schwartz (2010, p.213), “o agir em competência vai certamente depender muito do que o meio oferece a vocês, como espaço de desenvolvimento de seus possíveis". Como se trata aqui de interação, a responsabilização pelos sucessos ou fracassos deve ser vista de maneira global, considerando a pessoa e a organização e não, como se faz cada vez mais, culpabilizando quem trabalha; 
- "O quinto (...): a ativação ou a duplicação do potencial da pessoa, com suas incidências sobre cada ingrediente" (p. 217). Diz respeito ao debate de normas que cada um vive em seu meio de trabalho para implicar-se na realização de algo, valendo-se de suas potencialidades, ao mesmo tempo em que as desenvolve. Trata-se dos usos por si e pelos outros que o trabalhador faz, cada vez melhor, ampliando sua capacidade e seu campo de ação. Nas palavras de Schwartz (2010, p. 218), "a partir do momento em que um meio tem valor para você, todos os ingredientes da competência podem ser potencializados e desenvolvidos";

- "O sexto (...): tirar partido das sinergias de competências, em situação de trabalho" (p. 219). Corresponde ao que o autor chama de 'Entidades Coletivas Relativamente Pertinentes' (ECRP), da capacidade de trabalhar e fazer florescer a equipe, de favorecer o fortalecimento dos laços entre os pares. Cada um assume sua responsabilidade, não abrindo mão das obrigações do lugar que ocupa, mas sempre convocando, reconhecendo e valorizando o papel dos outros membros.

\section{A pesquisa e o seu método [2]}

O método utilizado no trabalho de campo buscou atingir a meta estabelecida nesta pesquisa, a saber: analisar a atividade de gerentes de hotéis a partir do desafio que Schwartz apresenta com a sua caraterização das competências.

Mas este estudo é também revelador da extrema dificuldade de aproximação do que ocorre realmente no dia a dia de uma atividade que se distingue pela autonomia numa relação de forte subordinação, isto é: sempre ameaçada pelo risco de ser avaliada com provas de insuficiência profissional, deixando por isso pouco espaço às interferências dos pesquisadores. 0 método que acabou por ser implementado foi por isso o possivel lembrando que "a extensão do pensável é extremamente reduzida pela estreiteza do possível” (Oddone, Re \& Briante, 1981, p. 215).

Participaram desta pesquisa 18 gerentes que trabalham em 11 hotéis ligados ao Convention \&Visitors Bureau [3], organização sem fins lucrativos cuja intermediação foi decisiva no acesso aos hotéis. Dentre os participantes, nove eram gerentes gerais, quatro eram gerentes de recepção/hospedagem, dois eram gerentes de conta/ comercial, um gerente de alimentos e bebidas e dois gerentes de eventos. Utilizamos entrevistas semiestruturadas, que foram realizadas no período de junho a novembro de 2010, com duração média de 50 minutos, gravadas em áudio integralmente. Em seu roteiro, havia questões que buscavam permitir uma maior aproximação à atividade dos gerentes de hotéis, procurando evidenciar por essa via, a partir da atividade linguageira, uma parcela dessas competências. $O$ contato com os participantes se deu por meio de indicações a partir da organização acima mencionada, utilizando os seguintes critérios de inclusão: ser gerente geral ou de outras funções hoteleiras (Comercial/Marketing, Alimentos \& Bebidas, Administrativo, Financeiro, Recepção, entre outras) e demonstrar interesse em participar da pesquisa. As entrevistas foram realizadas nos próprios hotéis.

37 Como o agir em competência supõe sempre uma ação situada e, portanto, nunca completamente antecipável (Schwartz, 2000), os pesquisadores planejaram a pesquisa de modo a articular a entrevista semiestruturada a observações da atividade. Essas técnicas seriam, portanto, complementares no processo de identificação das competências. Contudo, as observações do trabalho dos gerentes não foram possíveis, pois, após contatar os hotéis, entendemos que, diante de um cotidiano de trabalho 
intenso e exaustivo dos gerentes, a observação da atividade se mostraria inviável. Consideramos então que, se a atividade não nos foi acessível a partir da observação, o foi através da fala dos gerentes, apoiando-nos assim em Guérin, Laville, Daniellou, Duraffourg e Kerguelen (2001) quando afirmam que a verbalização do trabalhador é de qualquer maneira essencial para que compreendamos o processo de trabalho em profundidade. Em outros termos, pensamos que alcançar as vivências práticas dos trabalhadores exige sempre ter acesso às suas palavras.

O roteiro de entrevista foi estruturado em três segmentos: o primeiro contemplou questões básicas de identificação do gerente; o segundo trouxe uma caracterização dos hotéis quanto às suas estruturas física e organizacional; e o terceiro, investigou, sob vários ângulos, a atividade profissional dos gerentes. Neste último segmento abordamos questões relacionadas a: trajetória profissional; formação escolar e profissional; atividades de um gerente, em suas dimensões prescrita e real; aspectos geradores de dificuldades no trabalho e, por outro lado, os que tornam o mesmo interessante. $\mathrm{Na}$ busca em compreender as competências, o referido roteiro possuía diferentes questões na tentativa de apreendê-las por variados caminhos. Investigou-se, por meio de questões específicas, as competências que os gerentes julgavam possuir e aquelas que precisariam adquirir ou desenvolver; eventos significativos enfrentados em sua atuação gerencial e para os quais acreditavam ter encontrado saídas originais; bem como, posicionando o gerente na condição de avaliador, as competências que consideravam essenciais para que um gerente de hotel fosse bem avaliado.

Após a sua realização, as entrevistas foram transcritas e analisadas a partir da análise de conteúdo temática na perspectiva de Laville e Dionne (1999). Isto é: o princípio da análise de conteúdo consiste em desmontar a estrutura e os elementos do conteúdo obtido para esclarecer suas diferentes características e extrair sua significação, ou seja, compreender as significações no contexto da fala, fazendo inferências ao seu conteúdo.

\section{Resultados e discussões}

\subsection{O domínio de protocolos (Ingrediente 1)}

No cerne das competências estão os aspectos peculiares daquela atividade, ou seja, aqueles que remetem ao fazer gerencial strictu sensu. Para tanto, é necessário apropriarse de um volume crescente de prescrições, sob a forma de padronizações, indicadores, planos de metas, o que traduz uma extensão sensível do conteúdo do trabalho gerencial. Embora, como defende Schwartz (2010, p. 87), “(...) para ser competente no trabalho, é preciso dominar estes protocolos" (o domínio técnico-conceitual), deve-se destacar que a responsabilidade gerencial nesse caso se amplia, especialmente em função dos processos de reestruturação que, ao simplificar as estruturas hierárquicas, tem como efeito a intensificação do trabalho. Demanda-se dos gerentes que sejam capazes de dominar protocolos cada vez mais complexos, que monitorem, além da sua equipe de operadores, indicadores de desempenho contábeis, financeiros, quadro (que é um atributo do trabalho gerencial considerado mais amplamente) no qual as variabilidades do mercado aliadas às demandas de lucro em um contexto de crescente concorrência geram pressões cada vez maiores (Davel \& Melo, 2005; Máximo, 2009). A preocupação com a rentabilidade do negócio e o seu controle impõe-se ao gerente de uma maneira inédita na história desse segmento gerencial. 
A gente trabalha com números, gráficos (...) tudo que eu faço é em cima de números. Eu fico às vezes horas e horas analisando números, analisando taxas de ocupações de períodos antigos, tentando fazer estimativa até pra criar tarifários (...) (Gerente 3).

41 Na fala do gerente acima se percebe uma competência que adquire relevância cada vez maior em consonância com as exigências de rentabilidade do capitalismo contemporâneo. Diremos que se trata da competência financeira, que remete à capacidade de conhecer as ferramentas contábeis, de analisar o comportamento financeiro das empresas em que trabalham, de traçar metas de ocupação hoteleira, de definir tarifas apelando para a memória das situações. $O$ caráter dinâmico do serviço hoteleiro impele-os a procurar sistematicamente novos caminhos para cumprir suas metas de trabalho. Muitos dos entrevistados expressaram o desejo de desenvolver competências que potencializassem sua atuação nesse aspecto (articulando os ingredientes 1,2 e 5). Se por um lado, necessitam dos conhecimentos teóricos; por outro lado, é necessário que eles façam continuamente as articulações entre esses conhecimentos teóricos e a realidade dinâmica dos hotéis, a qual estão submetidos, o que remete ao ingrediente 3.

42 A competência em idiomas, especialmente o inglês, foi apontado também pela maioria dos gerentes como uma competência crucial nesse ramo. Comunicar-se verbalmente ou por escrito, de maneira adequada, com hóspedes estrangeiros constitui uma variável determinante nos serviços turísticos e, especialmente, hoteleiros. Muitas empresas exigem dos profissionais o domínio de um segundo ou mesmo de um terceiro idioma.

Mas, neste plano do dominio técnico-conceitual, foi possível verificar ainda a exigência de uma competência relacionada à área de alimentos $\boldsymbol{e}$ bebidas, que compreende uma diversidade de atividades, tais como: a confecção de cardápios; a escolha do tipo de serviço gastronômico mais adequado a cada ocasião; o controle sobre os custos dos insumos; os serviços de compras; a questão do armazenamento e controle dos alimentos, segundo os parâmetros estabelecidos pela vigilância sanitária: gestões relativas à qualidade do produto ofertado pelo hotel com o intuito de obter a satisfação do cliente. Embora do gerente geral não se exija profundidade no domínio dessas funções, já que existem pessoas (em alguns casos gerências) designadas para tal, é, no entanto, importante que possua uma base de conhecimentos nessa área que possibilite intervenções quando se mostrarem necessárias. Obviamente quanto menor o porte do hotel, mais domínio é exigido do gerente geral no tocante a função "Alimentos \& Bebidas".

Enfim, outra competência levantada aqui relaciona-se a área comercial/marketing que envolve o domínio de técnicas como as de prospecção de mercados, de relacionamento com a clientela que favoreça a fidelização, de monitoramento constante da ocupação hoteleira, tendo em vista a adequação da estratégia de atração de clientes - como enunciado na fala do Gerente 4, a seguir: "Estou me desenvolvendo melhor agora na parte de alimentos e bebidas e tenho que aprender a parte comercial." (Gerente 4).

\subsection{As variabilidades sempre presentes (Ingrediente 2)}

No entanto, o domínio das competências previstas está muito longe de ser suficiente para dar conta das situações do dia a dia de uma organização de serviço, já que as 
variabilidades constituem um atributo consubstancial a qualquer trabalho, mostrandose intensamente presente no setor hoteleiro. O trabalhador além de dominar os procedimentos de uma vasta gama de tarefas, precisa estar atento ao que há de inédito em cada situação.

Desta forma, os gerentes de hotéis, como os trabalhadores de uma forma geral, são impelidos a lidar com situações limites, imprevistas e desafiadoras. Este caráter enigmático da atividade coloca desafios para os gerentes que são os de diagnosticar adequadamente os problemas e tomar as melhores decisões em cada situação, mostrando-se mobilizados para atuar naquele meio, podendo, desta forma, desenvolver, duplicar as competências que já possui. Um dos gerentes evidencia o aspecto inusitado das demandas da atividade e a gestão do trabalho para dar conta das necessidades dos clientes:

Vieram (...) empresários, tinha um monte de gente e eram seis dias de evento e tinha uma sala de musculação, que a gente estava ampliando. O hotel realmente era lindo, equipamentos de última geração e nessa sala foi feito um trabalho de piso superficial, para educação física, pilates, essas coisas, e não tinha sala pra colocar o CPD dos caras, só tinha essa sala. Eu falei: 'Olha meu amigo, não tem problema não! Deixa eu ver quanto eu vou faturar'. Calculei quanto tinha de piso. 0 piso não era lá essas coisas. Quanto custa um piso? Sei lá! Eu consultei o meu chefe, vi a relação custo-benefício, ele liberou e você pode montar as coisas aqui e puxa e tal. Montaram uma estrutura de arrepiar. Isso foi na terça-feira e terminava num domingo. A hospedagem ocorreu maravilhosamente bem: café da manhã, almoço, coffe-break, jantar, tudo. Aí tinham até uma forma de fazerem um descanso (Gerente 9)

No setor de hotelaria, os imprevistos ocorrem de forma permanente, já que nunca se sabe que hóspedes aparecerão, assim como os problemas que poderão surgir com os funcionários, instalações e fornecedores. Os gerentes nos ofereceram exemplos de inúmeras situações que poderíamos considerar excepcionais, não corriqueiras, eventos verdadeiramente significativos, que exigiram um grande esforço de análise e a montagem de um plano de superação complexo que efetivamente desafiou a competência desses gerentes e, em muitos casos, revelou aos próprios algumas capacidades que ignoravam possuir. As soluções precisavam atender critérios que não são fáceis de conciliar. O horizonte dessas situações é bastante variado, algumas delas inclusive não pudemos dar publicidade por razões éticas, mas a nós, pesquisadores, impressionou bastante a capacidade desses gerentes de encontrar saídas sob medida, deixando a todos satisfeitos, valendo-se da equipe de funcionários do hotel, assim como de outros hotéis.

(...) ele não tinha direito "frente mar", eu consegui pra ele dentro das nossas parcerias e aí nem entramos no mérito da discussão. (...) A recepção ligou: tem disponibilidade. Então bota o cliente lá e depois a gente resolve. É não deixar o cliente sentir (...) (Gerente 9)

As falas dos gerentes, descritas anteriormente, evidenciam como as variabilidades são geridas: são iniciativas que resolvem o problema sem, entretanto, deixar que o cliente perceba as negociações internas e externas encetadas, seja internamente à equipe do hotel, seja externamente, com os parceiros da rede hoteleira. Esta competência de gestão dos imprevistos permite aos gerentes desembaraçarem-se dos eventos com elegância, com discrição, sem estardalhaço, sem operações bruscas que chamem 
atenção, o que pode ser fatal para a imagem do hotel com todos os efeitos que isso acarreta. O ambiente hoteleiro é sem dúvida uma escola nessa modalidade de competência.

Complementarmente, o Gerente 5 explicita uma competência que se apresenta determinante para o gerente de hotel na atualidade, ou seja, conhecer o próprio negócio, a estratégia que lhe serve de norte, o ambiente econômico no qual opera, as suas peculiaridades organizacionais: esta competência estratégica envolve, portanto, o domínio de elementos econômicos, organizacionais, operacionais, numa sequência que vai do geral ao particular, de forma articulada.

Olha, a primeira coisa que eu acho importante também é a questão de você saber analisar o negócio, (...) você ter o conhecimento do seu negócio, saber o que tá acontecendo dentro no seu hotel. (Gerente 5)

\subsection{Ingrediente 3: a posição estratégica dos gerentes e a conjugação dos Ingredientes 1 e 2 no dia a dia}

É talvez nesse âmbito que localizamos uma importante fonte de prescrição do trabalho gerencial, ou seja, a sua capacidade de compreender e dar concretude às diretrizes da organização contidas no seu plano estratégico. Traduzir tais expectativas em indicadores, em objetivos e metas a atingir, ter a consciência de quais ações são necessárias para viabilizar o horizonte esperado para a organização é, certamente, a expectativa principal dos dirigentes em relação aos gerentes de hotéis. Em alguns casos, em hotéis controlados por redes nacionais, mas sobretudo, internacionais, tais indicadores estão pré-determinados pela administração central que contrata inclusive pseudo-hóspedes munidos de extensas listas de indicadores que guiarão a avaliação daquele hotel. Nesses casos, o trabalho dos gerentes resume-se em atender esses indicadores, sob os quais não exerce nenhum tipo de controle.

51 Quer isto dizer que o gerente deve ser capaz de intervir de modo a permitir a cada membro da equipe sentir-se também participante da estratégia da empresa, isto é, favorecer que o meio de trabalho seja mais ou menos amistoso ou conflituoso (Vries, 1997). Para fazê-lo com sucesso, precisa ter um bom conhecimento teórico sobre a estruturas do turismo e hoteleira, sobre finanças, dentre outras, conjugando-as com as variabilidades que se manifestam em seu dia a dia.

Um dos participantes mencionou que a experiência como gerente em várias organizações hoteleiras e em diversos setores do hotel o deixou mais preparado para sua atividade, favorecendo que compreendesse melhor tanto os protocolos quanto as situações concretas. Não se trata aqui de defender um percurso no qual a quantidade de experiências constitua condição para a aquisição da competência, mas sim de frisar a necessidade de enfrentamento de uma variedade de situações para que a experiência se converta em possibilidade formativa.

$\mathrm{Eu}$ acho que um bom gerente geral tem que ter trabalhado em várias organizações, então, quanto maior experiência tiver, de preferência empresa estrangeira e brasileira de outros Estados e, no caso de gerente geral, ter trabalhado em outros diversos setores (Gerente 6). organizacional hoteleira, ou seja, trabalhando na recepção/atendimento, um lugar que 
permite uma compreensão do funcionamento global do hotel, e depois evoluíram para outras áreas até galgar a gerência geral ou outro nível gerencial do hotel. Mas somente conseguiram ascender na estrutura do hotel se, ao lado da experiência que foram adquirindo, realizaram também formação teórica.

Como eu te falei anteriormente, eu não sou formada em hotelaria. (...) Então, uma das características aqui do hotel é aproveitar as pessoas daqui pra novas oportunidades, preparar etc. Mas, é como eu digo, a gente tá sempre buscando estudar, procurando se inteirar pra fazer o melhor que a gente pode. (Gerente 5)

54 A fala do Gerente 6 ilustra de modo representativo o caráter do desenvolvimento da experiência no trabalho, a partir do exercício da atividade, revelando que a competência é tributária do saber-fazer concreto, ancorada nos conceitos. Potencializar, duplicar as competências, não é uma operação meramente de repetir o anteriormente estocado, mas para fazê-lo precisa considerar as singularidades da nova situação concreta que se apresenta. Portanto, a competência é re-criação permanente. Neste sentido é da ordem da prática e quanto mais experiência mais potencializado o trabalhador estará para enfrentar as infidelidades do meio.

As competências estão relacionadas com as situações concretas de trabalho. É preferencialmente na atividade, no enfrentamento cotidiano dos eventos, onde se desenvolvem competências ou então se evidenciam lacunas, discrepâncias a serem trabalhadas num processo de formação, sempre em conexão direta com os acontecimentos.

Todavia, acreditamos que uma formação que concilie tal conhecimento adquirido na prática com o conhecimento teórico, poderia atuar sinergicamente no desenvolvimento desses gerentes, com benefícios para eles e para os hotéis, como fala o Gerente 8:

no dia-a-dia, onde você vai ter que aprender que um gerador tem tantos cavalos de potência, o que ele agüenta, o que é que ele não agüenta, tratamento de água. Então, eu acho que foi bem válida a formação, é uma coisa direcionada, você já vai mais ou menos onde ta pisando e cada situação que vier diferente.

Os gerentes de hotéis fomentam sua experiência no exercício de sua atividade, espaço de variabilidades e de (re)criação permanente. Um participante (Gerente 2) explicita um modo determinado de gerir as situações de trabalho no qual a experiência, aguçando a sensibilidade, permitiu, por intermédio do acionamento da inteligência prática (Dejours, 2007), o fortalecimento da capacidade de antecipação, de detecção, por meio de sinais muitas vezes frágeis, de demandas latentes dos hóspedes e dos empregados do hotel. Esta é uma competência de inovação que está relacionada, mas não de forma exclusiva, com as micro decisões que precisam ser tomadas no cotidiano. Elas traduzem a criatividade e a inventividade que florescem de cada situação enfrentada e que se materializa em novas ideias, proposições, projetos, técnicas, savoirfaire, savoir-vivre, arranjos organizacionais, enfim um patrimônio que contribui para atualizar permanentemente o meio profissional hoteleiro, como ilustra a fala do gerente 8: "você vai trabalhar com a regra, mas você tem que ter o bom senso e perceber como você vai administrar isso daí". 


\subsection{Ingrediente 4 e os debates de normas e valores}

para aquisição das demais, diz respeito à implicação do gerente com o seu trabalho, o que remete ao Ingrediente 4 daqueles apontados por Schwartz (2010), a saber: o debate de valores e de normas, considerando-se as impostas e as instituídas na atividade. Sem a identificação com o trabalho, sem o impulso do querer, o processo de aquisição de competências não avança ou pelo menos não se dá na mesma intensidade de quando existe implicação. Obviamente, esse movimento não é nunca apenas do gerente. Para que se sustente, é necessário que o hotel ofereça condições para que ocorra essa mobilização subjetiva, assim como para que ela se sustente, em um debate de valores. Mas no dia a dia, nem sempre a organização oferece instrumentos que possam manter os gerentes motivados, já que muitas vezes recebem baixos salários e precisam manter motivados os funcionários que recebem ainda menos que eles, como se apresenta na fala do gerente 7:

difícil em um dia de trabalho é você conseguir tá sempre com a equipe realmente motivada, dado que na hotelaria se paga muito pouco, a maioria ganha o salário mínimo, setores grandes como a governadoria tem muita picuinha, muito leva e trás entre os colaboradores, então há brigas, há situações né?

O trabalho dos gerentes de hotéis exige uma grande dedicação, fazendo com que muitas vezes tenham que se mudar de cidade para acompanhar um novo empreendimento de uma rede hoteleira, o que gera conflito entre os valores dos gerentes com o que o trabalho lhes demanda: "olha não é nem no meu trabalho, eu acho que na minha carreira é a questão de morar longe das pessoas, eu acho que é isso, porque o trabalho em si é corrido, é uma dedicação muito grande (Gerente 6). Essa exigência do trabalho, inclusive, foi apontada por um dos entrevistados como uma fonte importante de sofrimento, já que restringe a possibilidade de criar raízes em determinado lugar, implicando dificuldades ao nível pessoal como, no caso de gerentes jovens, encontrar alguém com quem possa constituir família ou estabelecer uma rede de amizades fora do meio profissional, entre outras.

Para Schwartz (2004), o gerir está presente em toda atividade de trabalho, já que trabalhar supõe sempre uma dimensão gestionária, seja da vida subjetiva, seja das relações com os outros e das contradições ali presentes - sendo que tal dimensão se dá em três polos: do orçamento do Estado e da gestão dos recursos públicos; dos gestores das empresas; da atividade. Quando o trabalhador é o próprio gerente, os níveis de gestão da empresa e o da atividade coincidem, de tal forma que cabe lançar luz às gestões ali presentes, como este artigo pretende abarcar.

\subsection{A ativação ou duplicação do potencial dos gerentes: Ingrediente}

5

61 Como argumentamos anteriormente, o domínio de protocolos não garante o sucesso diante dos desafios colocados pelos imprevistos no dia a dia. Isto pode ser ocasião tanto para detectar demandas de aquisição de competências quanto para, no próprio processo de enfrentamento da situação, desenvolver competências, realizando "a ativação ou a duplicação potencial da pessoa" (Schwartz, 2010, p. 217), quanto ainda 
para surpreender-se com a emergência e fortalecimento de suas potencialidades (Ingrediente 5), como se apresenta na fala abaixo:

Um dia desses, estava tudo muito calmo aqui e um hóspede deu um "piripaque" [4] lá na piscina, e como fazer isso pra não chamar atenção dos demais; ainda bem que não veio a óbito aqui no hotel. Mas se viesse a falecer na ambulância a caminho do hospital? Isso não está no script ou no curso que você faz (...). Como sair disso de uma forma elegante que não seja alarmada, que não deixe as pessoas em pânico e, ao mesmo tempo, com medo? Vai que descobrem que saiu um "presunto" daqui e depois ninguém quer ir pra um "hotel-fantasma". Então, tem dessas coisas. (Gerente 11) [5]

Nesta fala podemos perceber também a gestão de um imprevisto por parte do gerente, que exigiu dele sua capacidade de definir o que fazer, de arbitrar os aspectos de resolução do problema, compreendendo a singularidade, o histórico do que se passava, utilizando seus conhecimentos para dar conta daquela situação específica. Ao fazer isto, ao mesmo tempo em que resolve uma situação, torna-se mais competente para resolver as situações seguintes, mesmo que diferentes daquela já resolvida. Esta competência de gestão dos imprevistos se erige, portanto, face às situações inusitadas do meio. É uma competência engendrada no trabalho vivo, pelas infiltrações do histórico, no dizer de Schwartz (2010). A iniciativa do gerente neste acontecimento mostra a insuficiência das normas antecedentes do setor, mas, sobretudo, evoca uma competência do histórico, composta por pontos de referência, conhecimentos mais ou menos intuitivos da vizinhança industriosa, antecipações do comportamento e das arbitragens dos próximos (Schwartz, 2000; 2010). Desta forma, a ativação de uma competência é intimamente ligada com o desenvolvimento de outras, tornando o trabalhador cada vez mais capaz de lidar com seu dia a dia, com as situações previsíveis e com os imprevistos.

As entrevistas mostram que no setor hoteleiro, as competências atualizam-se continuamente em face do caráter dinâmico das situações de trabalho. Os conhecimentos técnicos precisam ser complementados, atualizados, renovados e alargados. Marca-se mais uma vez a importância do ingrediente 2 (lidar com o singular) para desenvolver as próprias competências, gerando a capacidade de ampliá-las (ingrediente 5). Os gerentes falam de competências adquiridas na linha do atuar, coordenar, gerir, ou seja, tomadas de iniciativas que se referem ao modo de gestão propriamente dito, que remetem ao cumprimento de metas nos mais diversos indicadores do hotel, desde a área de limpeza aos resultados financeiros. Desenvolvem na própria organização, no enfrentamento dos imprevistos, uma capacidade para diagnosticar com rapidez os problemas, inclusive para antecipar-se a alguns deles, utilizando-se de conhecimentos teóricos (ingrediente 1), conhecimentos práticos (ingrediente 2), e da articulação entre ambos (ingrediente 3). Esta capacidade do gerente desenvolvida por meio de seus pontos de referência, faz emergir saberes armazenados para o enfrentamento das variabilidades. 0 gerir, nesta situação, aflora das competências estocadas nos diversos níveis do corpo-si (Schwartz, 2000), que permite a ele perceber certas situações e encontrar soluções, como enuncia um dos gerentes a seguir:

Aqui a gente já teve um imprevisto de uma placa solar, já quebrou e comprometeu o fornecimento de água quente no hotel inteiro, então gera um aborrecimento, aí já entramos em contato com o fornecedor, então tentamos minimizar o máximo a questão do tempo, é um sinal de tv, tudo 
isso gera insatisfação pro hóspede, a maioria das coisas a gente tenta resolver com o fornecedor (Gerente 9).

\subsection{0 caráter coletivo da competência (Ingrediente 6)} problemas do cotidiano nos hotéis. 0 modo de gestão que se aplica na organização hoteleira aponta para a importância da relação dos gerentes com os outros funcionários. Estar aberto para a participação dos funcionários é uma exigência no setor hoteleiro que necessita de um empenho coletivo no sentido de oferecer o melhor serviço aos hóspedes. Os funcionários, assim valorizados, podem auxiliar na gestão do trabalho, com sugestões de melhorias no modo de funcionamento do hotel. Há, em vários casos, a valorização do saber fazer desses funcionários e um estímulo ao trabalho em equipe, favorecendo a constituição de "entidades coletivas relativamente pertinentes" (Schwartz, 2010, p. 218). A resolução de determinados problemas faz florescer a equipe, propicia a potencialização dos laços entre os pares. Convocar o coletivo é reconhecer e valorizar o papel dos diversos protagonistas da atividade (Schwartz, 2010).

(...) hoje na nossa rede, várias ideias que hoje nós vamos aplicando são sugeridas por camareiras, por meus garçons, são eles que vivenciam o dia-adia, eles que sabem as dificuldades, são eles que sabem o que o cliente tá gostando ou não tá gostando do seu negócio, então se você não faz uma reunião onde eles exponham isso, muitas vezes você não tem como, claro no meu caso eu tenho a pesquisa de participação, mas algumas coisas ainda fogem e às vezes é dele que você consegue, a partir da sua observação que você consegue isso, então eu acho que quem não pratica a gestão dessa forma perde bastante (Gerente 5)

A competência relacional/política é a capacidade do indivíduo de se relacionar com vários públicos, tendo em vista uma produção/um serviço que gere satisfação nesses diferentes públicos. Nesta linha, os gerentes apontaram a necessidade de saber lidar com as demandas desses vários públicos, sejam eles hóspedes, empregados, fornecedores, terceirizados, assistência técnica, representantes de outros hotéis:

\footnotetext{
(...) não só o conhecimento financeiro, mas sociológico também, porque a gente lida muito com o ser humano aqui, demais até, seja com o hóspede, com o empregado, com o fornecedor ou com o cliente (Gerente 5)

A gestão de pessoas é isso, é o coaching, saber com quem você tá trabalhando, saber quem é essa pessoa, qual que é vida dela em particular, o que isso influencia no lado profissional dela, entender quais são as fraquezas e fortalezas dessas pessoas e saber trabalhar com isso (Gerente 7)

A coisa mais complexa que tem é lidar com gente. E cada cabeça é um mundo, cada um pensa de um jeito diferente. Manter todo esse pessoal ordenado não é fácil (Gerente 13)
}

Especificamente na relação com os empregados, pontuaram a necessidade de gerenciar respeitando-os como pessoas, o que certamente favorece o Ingrediente 6. Convém aqui salientar que, além do que apareceu nas falas dos gerentes no que diz respeito à capacidade de tratar bem o outro, evidenciamos isso no trato que eles tiveram conosco, pesquisadores. Depois de formalmente autorizados a entrar nos hotéis, era, quase sempre, muito difícil conseguir marcar um horário com os gerentes, que têm seu dia a 
dia sempre com muitas tarefas. No entanto, quando conseguíamos nos encontrar com eles, a receptividade era sempre excelente. A competência relacional, indispensável no ramo hoteleiro, que permite que o hóspede se sinta "em casa", aparecia na forma como éramos recebidos. Por exemplo, quando tentamos marcar um horário com o Gerente 9 , ele disse: "tá bom, pode vir, mas com uma condição: que você venha tomar o café da manhã comigo". Também o gerente 5 , ao receber o pesquisador, em sua sala com diversos adereços do Flamengo (o clube de futebol com a maior torcida do Brasil), antes de entrar propriamente na entrevista, começou a falar de futebol. Quando o pesquisador disse que também torce para o mesmo time, o gerente contou várias histórias ligadas ao esporte, contando que já recebeu ex-presidente de um clube rival, etc. De fato, aqui o trabalho se mostra efetivamente como atividade subjetivante, que transforma quem o realiza (Dejours, 2007), tornando-os extremamente receptivos.

As competências adquiridas estão abertas à atualização, pois não são estanques, pontuais, já que a função de gerente requer sempre manter relações intersubjetivas no trabalho. Os gerentes explicitaram que é necessário compreender problemas pessoais enfrentados pelos funcionários do hotel, o que facilita o bom trabalho desse funcionário, permitindo que ele mobilize suas competências quando requeridas. 0 trabalho do gerente implica na capacidade de saber lidar com as pessoas e ter controle do próprio comportamento. No exercício destas competências o gerente faz uso de si por si e uso de si pelos outros (Schwartz, 2010).

Em síntese, os dados demonstram que temos nas situações de trabalho dos gerentes de hotéis em João Pessoa e Campina Grande competências que estão previstas e competências que brotam das situações de trabalho. Quando confrontados com as infidelidades do meio, os gerentes renormatizam as competências previstas e, por outro lado, tornam-se conscientes de competências que possuíam, mas ignoravam, ou então são provocados pela necessidade de desenvolverem competências para estarem à altura dos desafios da atividade. 0 meio é sempre, em parte, imprevisível, de tal forma que novas competências são requeridas para dar consecução às atividades. No trabalho sempre existem vazios de normas que convocam a iniciativa dos gerentes. Em consequência, as novas competências vão se firmando na profissão, enriquecendo as normas antecedentes.

\section{Considerações finais}

As análises acima expostas mostram que as competências mobilizadas pelos gerentes de hotéis são construídas em face das situações reais de trabalho, que permitem que sejam adquiridas, desenvolvidas, atualizadas. Evidenciamos que os gerentes estão cotidianamente buscando saídas para as situações inusitadas, as variabilidades e exigências dos clientes, procurando e criando formas de superar os eventos que se apresentam. $O$ cargo de gerente é, na verdade, essencialmente marcado por situações imprevistas, oportunizando, exigindo, o uso rápido da inteligência da prática em eventos inesperados, o desenvolvimento de competências que se traduzem em iniciativas, responsabilidades e tomadas de decisões: a cautela, a agilidade e a astúcia, prevalecem como formas de agir na gestão das variabilidades do trabalho gerencial.

Este agir em competência requer claramente o domínio da experiência acumulada no trabalho. Por isso a trajetória profissional se revela fundamental, possibilitando, nos casos bem sucedidos, um largo repertório de recursos pessoais e organizacionais que se 
concretizam numa competência acumulada, portanto de experiência, integrando as qualidades exigidas para a realização da atividade.

71 Embora não pudemos, no âmbito desta pesquisa, observar a atividade desses profissionais, e assim melhor compreender as suas competências quando elas estão no movimento de sua própria produção, acreditamos que os resultados da pesquisa permitiram progredir na caraterização da profissão do gerente de hotel, passando a conhecer as dificuldades e anseios que se tornam presentes em seu dia a dia de trabalho.

Mas uma questão emerge deste estudo, que coloca em debate os obstáculos encontrados pelos gerentes na procura de acções de formação profissional susceptíveis de os ajudar na aquisição ou na consolidação de alguns aspetos da sua competência. A questão é dupla e se relaciona, por um lado, com a necessidade em conceber cenários que levarão em conta a atividade real de trabalho daqueles que estão no seio da empresa (Teiger \& Lacomblez, 2013), e, por outro lado, com o fato desta preocupação não fazer parte das prioridades dos proprietários de hotéis, deixando a questão da formação desses profissionais como sendo apenas da sua responsabilidade, sem contrapartida.

73 Assim, os gerentes não vislumbram outra possibilidade senão procurarem cursos por conta própria, arcando quase sempre inteiramente com os ônus financeiros - cursos esses que, além disso, se revelam muitas vezes desconectados de sua realidade, acabando por não permitir um desenvolvimento das qualidades profissionais procuradas, e concluindo-se, como o realçou Cornu (2001), por uma perda de tempo e de investimento para os trabalhadores.

De modo geral, as formas contemporâneas de gestão tendem a diluir os laços de cooperação destruindo os coletivos e deixando cada um mais isolado e enfraquecido diante da organização do trabalho (Dejours, 2015). E, mais preocupante ainda, tais formas de gestão procuram se colocar como se fossem as únicas possíveis, como se não se pudesse governar o trabalho de modo alternativo. As evoluções na gestão hoteleira e na profissão dos seus gerentes evidenciam igualmente os riscos de uma relação salarial em que a autonomia se debate de forma constante com uma forte subordinação. Pensamos que a questão da formação desses profissionais é um bom revelador dessa relação. E cremos que esta pesquisa, lançando luz sobre o trabalho gerencial e suas dramáticas nos usos de si, poderá sustentar novas intervenções nos campos das políticas para o turismo, do planeamento de ações de formação, na renovação de alguns principios da organização do trabalho nos hoteis.

Essas conclusões resultam obviamente das potencialidades teórico-metodológicas do modelo dos ingredientes proposto por Schwartz. Mas a reflexão crítica relativa às razões que tenham sustentado um interesse crescente para certo tipo de mapeamento das competências, não deixou de ter também a sua utilidade heurística no evoluir da nossa reflexão. 


\section{BIBLIOGRAFIA}

Cornu, R. (2001). Education, savoir et production. Bruxelles: Editions de l'Université de Bruxelles.

Davel, E., \& Melo, M. C. O. L. (2005). Singularidades e transformações no trabalho dos gerentes. In E. Davel \& M.C.O.L. Melo (Orgs.). Gerência em ação: singularidades e dilemas do trabalho gerencial (pp. 29-66). Rio de Janeiro: FGV.

Dejours, C. (2007). o fator humano. Rio de Janeiro: FGV, 2007.

Dejours, C. (2015). Le choix, Souffrir au travail n'est pas une fatalité. Paris: Bayard.

Fernandes, L. Nogueira, M. Cruz, M. Figueiredo, R. \& Ávila, R.. (2010). Certificação de pessoas para o setor de turismo: hotelaria. Observatório de Inovação do Turismo: Revista Acadêmica, 5(4), $1-18$.

Gadrey, J. (2001). Emprego, produtividade e avaliação do desempenho dos serviços. In M. S. Salerno (Org.). Relação de serviço: produção e avaliação (pp. 23-65). São Paulo: Editora do SENAC (Série Trabalho e Sociedade).

Guérin, F. Laville, A., Daniellou, F. Duraffourg, J. \& Kerguelen, A. (2001). Compreender o trabalho para transformá-lo : a prática da ergonomia. São Paulo : Editora Edgard Blücher.

Gorini, A. P. F., \& Mendes, E. F. (2005). Setor de turismo no Brasil: segmento de hotelaria. BNDES Setorial, Rio de Janeiro, 22, 111-150.

Heloani, R. (2003). Gestão e Organização no capitalismo globalizado: História da manipulação psicológica no mundo do trabalho. São Paulo: Atlas.

Jobert, G. (2003). A profissionalização: entre competência e reconhecimento social. In M. Altet; P. Perrenoud \& L. Paquay(Orgs.), A profissionalização dos formadores de professores (pp. 221-232). Porto Alegre: Artmed.

Laville, C., \& Dionne, J. (1999). A construção do saber: manual de metodologia da pesquisa em ciências humanas. Porto Alegre: ARTMED.

Lima, C.M.P., \& Zambroni, P. (2013). As competências dos profissionais da área de Gestão de Pessoas. Verlag: Novas Edições Acadêmicas.

Luci, F., \& Szlechter, D. (2014). La sociologia del management en Argentina: debates para un campo en formación. Revista Latino-americana de Estudos do Trabalho, 19, 32, 113-156.

Mascia, F.L. (2007). O trabalho da supervisão: o ponto de vista da ergonomia. In P. Falzon (ed.), Ergonomia (pp. 609-625). São Paulo: Ed. Blucher.

Máximo, T.A.C.O. (2009). Super-homem moderno: análise da relação trabalho/saúde de gerentes de bancos públicos e privados. Dissertação de Mestrado. Programa de Pós-graduação em Psicologia Social da Universidade Federal da Paraíba.

Máximo, T.A.C.O. (2012). Significado da formação e inserção profissional para gerentes e aprendizes egressos do programa jovem aprendiz. Tese de Doutorado. Programa de Pós Graduação em Psicologia Social. Universidade Federal da Paraíba.

Oddone, I., Re, A., \& Briante, G. (1981). Redécouvrir l'expérience ouvrière. Vers une autre psychologie du travail. Paris: Éditions sociales. 
Ribeiro, M. A. (2009). Psicologia e gestão de pessoas: Reflexões críticas e temas afins (ética, competência e carreira). São Paulo: Vetor.

Schwartz, Y. (2000). Le paradigme ergologique ou um métier de philosophe (pp. 479-503). Toulouse: Octarès Editions.

Schwartz, Y. (2004). Trabalho e gestão: níveis, critérios e instâncias. In M. Figueiredo, M. Athayde, J. Brito, \& D. Alvarez (orgs.), Labirintos do trabalho: interrogações e olhares sobre o trabalho vivo (pp.23-36). Rio de Janeiro: DP\&A.

Schwartz, Y. (2010). Uso de si e competência. In Schwartz, Y. \& Durrive, L (orgs), Trabalho \& Ergologia: Conversas sobre a atividade humana (pp. 205-221). Niterói: Editora da UFF.

Silva, A. R, \& Mota, K. C. N. (2013). Competências para o mercado de trabalho em turismo e hotelaria: Perfil dos profissionais requerido em Fortaleza. Conex. Ci. e Tecnol, 7(1), 9-30.

Soares, S.A. (2014). Competências gerenciais na indústria: analisando o prescrito e o real. Dissertação de mestrado. Programa de Pós Graduação em Psicologia Social. Universidade Federal da Paraíba.

Spector, P. (2002). Psicologia nas organizações. São Paulo: Saraiva.

Stroobants, M. (2006). Competência. Laboreal. II, 2, 78-79. http://laboreal.up.pt/pt/articles/ competencia/

Teiger, C. \& Lacomblez, M. (Coord., 2013). (Se) former pour transformer le travail: dynamique de constructions d'une analyse critique du travail. Québec/Bruxelles: Presses de l'Université Laval/PUL/ European Trade Union Institute/ETUI.

Vries, M. K. (1997). Os gerentes podem deixar seus subordinados loucos. In C. V. Bergamini, \& R. Coda, Psicodimânica da vida organizacional: motivação e liderança (pp. 300-318). São Paulo: Atlas.

Zarifian, P. (2001a). Comunicação e subjetividade nas organizações. In E. Davel, \& S.C. Vergara

(Orgs.), Gestão com Pessoas e Subjetividade (pp. 151-170). São Paulo: Atlas.

Zarifian, P. (2001b). Objetivo Competência: por uma nova lógica. São Paulo: Atlas.

\section{NOTAS}

1. Não obstante, é preciso reconhecer que na atividade de operação de telemarketing, que nos últimos tempos tem gerado uma quantidade impressionante de postos de trabalho no Brasil e cujo trabalho está ancorado no uso da palavra, a taylorização alcançou níveis insuspeitados, a ponto de Zarifian (2001b) afirmar que, nesse caso, tal processo foi ainda mais violento que aquele registrado nas fábricas, pois o controle que antes se exercia apenas sobre o gesto, agora se exerce também sobre a palavra, produzindo uma linguagem codificada que impede ou dificulta as tentativas de responder de forma singular às demandas dos clientes/usuários.

2. O projeto foi aprovado pelo Comitê de Ética em Pesquisa da Universidade Federal da Paraíba e seguiu os preceitos da Resolução 96/1996 do Conselho Nacional de Saúde, que regia, à época, a pesquisa envolvendo seres humanos.

3. É uma organização sem fins lucrativos, que trabalha pelo desenvolvimento social, econômico e turístico através do turismo de eventos e negócios.

4. Expressão popular do Brasil, que caracteriza uma espécie de mal estar, geralmente ocasionado de forma inesperada, e que pode levar à morte.

5. 0 entrevistado faz alusão a um episódio em que um hóspede se sentiu mal na piscina do hotel, foi hospitalizado, mas acabou falecendo no hospital. 


\section{RESUMOS}

O presente artigo tem como objetivo discutir a noção de competência valendo-se do referencial teórico da Ergologia, que considera a competência como um agir aqui e agora, um movimento da atividade. A pesquisa empírica, de cunho qualitativo, foi realizada junto a 18 gerentes do setor hoteleiro em João Pessoa e Campina Grande - PB, Brasil, valendo-se de um roteiro de entrevista semiestruturado. Evidenciou-se que as competências mobilizadas pelos gerentes entrevistados são construídas nas situações reais de trabalho, sendo adquiridas, desenvolvidas e atualizadas em um cotidiano de trabalho exigente e repleto de variabilidades. Verificou-se que o trabalho do gerente exige o manejo permanente de imprevistos, o que requer decisões rápidas e criativas. Demanda-se ainda desses profissionais a gestão das situações de trabalho com cautela e astúcia, formas de agir que se valem de diversos ingredientes para o exercício competente de sua atividade.

Este artículo tiene como objetivo discutir la noción de competencia sobre la base del marco teórico de la Ergología, que considera la competencia como un acto aquí y ahora, una actividad de movimiento. La investigación empírica, un estudio cualitativo, se llevó a cabo partiendo de entrevistas con 18 gerentes de la industria hotelera en João Pessoa y en Campina Grande, Paraíba, en Brasil. Los datos muestran que las habilidades desplegadas por los gerentes entrevistados se construyen en situaciones reales de trabajo, que se adquieren, desarrollan y actualizan en lo cotidiano de un trabajo exigente y sumamente variable. Se encontró que el trabajo del gerente requiere una gestión continua de lo imprevisto con decisiones rápidas y creativas. En el trabajo de estos profesionales también se requiere cautela y astucia, maneras de actuar que utilizan varios ingredientes para el ejercicio adecuado de su actividad.

L'objectif de l'article est de discuter la notion de compétence selon le cadre théorique de l'Ergologie qui la considère en tant qu'un agir ici et maintenant, un mouvement d'activité. La recherche empirique, dans une approche qualitative, a été réalisée auprès de 18 managers du secteur hôtelier à João Pessoa et à Campina Grande, PB, Brésil. Ceux-ci ont répondu à un entretien semi-directif. Il a été observé que les compétences mobilisées par les managers sont essentiellement construites dans le cours des situations de travail. Elles sont acquises, développées et actualisées, dans un quotidien extrêmement exigeant et variable. La fonction de manager requiert une gestion permanente d'imprévus, avec prise de décision rapide et créative tout en faisant preuve de prudence et de sagacité. Ce sont des façons d'agir qui convoquent différents ingrédients de compétence permettant l'exercice de leur activité.

This paper's objective is to discuss the notion that competence makes use of the theoretical reference to ergology considering competence as acting here and now, activity in motion. Empirical research of a qualitative nature was carried out with 18 managers from the hotel sector in João Pessoa and Campina Grande - PB, Brazil, making use of a semi structured interview script. The findings show that these managers' competencies are based on real work situations they have encountered, developed and updated in a demanding workplace full of variability. It was established that the manager's job demands constant handling of unforeseen situations, which requires rapid and creative decisions. It also calls for these professionals to manage work situations with caution and astuteness, courses of action that make use of different components for the competent practice of their activity. 
ÍNDICE

Keywords: competence, management, hotel sector

Mots-clés: compétence, manager, secteur hôtelier

Palabras claves: competencia, gerencia, industria hotelera

Palavras-chave: competência, trabalho gerencial, hotelaria

\section{AUTORES}

\section{EDIL FERREIRA DA SILVA}

Programa de Pós-graduação em Psicologia da Saúde e Programa de Pós-graduação em Serviço Social, Universidade Estadual da Paraíba (UEPB), Av. , Sapé, 434 - Apto 502, Manaíra, João Pessoa PB, Brasil

edilsilva@uol.com.br

\section{ANÍSIO JOSÉ DA SILVA ARAÚJO}

Grupo de Pesquisa Subjetividade e Trabalho (GPST), Departamento de Psicologia - Centro de Ciências Humanas e Letras, Universidade Federal da Paraíba (UFPB), Cidade Universitária, João Pessoa - PB, Brasil, CEP 58051-900

anisiojsa@uol.com.br

\section{FRANCINALDO DO MONTE PINTO}

Grupo de Pesquisa Trabalho, Saúde e Subjetividade, Programa de Pós-graduação em Psicologia da Saúde , Universidade Estadual da Paraíba (UEPB), Rua Baraúnas, 351 - Bairro Universitário, Campina Grande - Paraíba, Brasil, CEP 58429-500

dumontepinto@uol.com.br

\section{PAULO CÉSAR ZAMBRONI-DE-SOUZA}

Grupo de Pesquisa em Subjetividade e Trabalho - GPST, Departamento de Psicologia, Universidade Federal da Paraíba, Cidade Universitária, João Pessoa - PB, Brasil, CEP 58051-900, paulozamsouza@yahoo.com.br

\section{EUDA KALIANI GOMES TEIXEIRA ROCHA}

Núcleo de Estudos do Trabalho (NUT), Departamento de Psicologia Universidade Federal de Pernambuco, Av. Afonso Olindense, 130, Cx. Postal 8026, Várzea - Recife - PE, Brasil, CEP 50.810.970

kalianirocha@gmail.com

\section{THAIIS AUGUSTA CUNHA DE OLIVEIRA MÁXIMO}

Grupo de Pesquisa em Subjetividade e Trabalho - GPST, Departamento de Psicologia, Universidade Federal da Paraíba, Cidade Universitária, João Pessoa - PB, Brasil thaisaugusta@gmail.com 